\title{
The Protection of Endangered Languages of Ethnic Minorities in Yunnan and the Inheritance of National Culture
}

\author{
Liu Juan \\ Yunnan Agricultural University, Kunming, Yunnan, China, 650201
}

Keywords: endangered language, Yunnan minority, cultural heritage

\begin{abstract}
As one of the main media of cultural communication, language is one of the most important and basic forms of expression of culture. At the same time, language can reflect the true meaning of culture. Culture and language are interdependent and influential in their respective development processes. From this aspect, under the situation and background of the world's emphasis on the protection of intangible culture and the inheritance of intangible culture, the investigation and research on the status quo of Yunnan minority languages and cultures, it is of great guiding significance to the protection of the endangered languages of ethnic minorities in Yunnan and the inheritance of national culture.
\end{abstract}

China has a long history and a long history of culture. The Han nationality and 55 other ethnic minorities live on the vast territory. According to incomplete investigations and statistics, there are more than 80 languages in use. Culture and language are interdependent and influential in their respective development processes. The two have special dialectical relationships as special social phenomena. Language inevitably arises, evolves and dies with the development of culture. Today, China's society is dominated by the Han people. Chinese has undoubtedly become the mainstream language and has been greatly developed. In contrast, minority languages are restricted by various factors and are in a very embarrassing position. However, with the development of society, people's vision have become more long-term, the understanding of cultural protection and inheritance has gradually deepened, and the voices concerning minority language and cultural protection are getting higher and higher. So how can we carry out relevant protection and inheritance work correctly and smoothly? The author selects the language and culture status of Yunnan minority nationalities to conduct investigation and research, analyzes and discusses the diversity of ethnic minority languages and cultures in Yunnan, the reasons for the formation of endangered dilemmas, and the protection and inheritance, and gives certain guiding opinions and feasible suggestions.

\section{The Diversity of Minority Languages and Cultures in Yunnan}

Located in the southwestern border of China, Yunnan is not only a settlement of ethnic minorities in southwest China, but also a border between China and Myanmar, Vietnam, Laos and 
other countries. Due to complex historical reasons, as well as topographical and other factors, Yunnan Province has become the province with the largest number of ethnic minorities in China. There are 26 indigenous peoples and 15 cross-border ethnic groups. The overall distribution shows the form of large scattered and small concentrated forms of large mixed and small settlements. At present, there are 22 minority languages in Yunnan, which are roughly classified into 4 language groups and 11 language branches in the two languages of Han and Tibetan. In the development of a few language cultures in Yunnan, at the time of the founding of New China, ethnic minorities maintained their own traditions. Although they were close to the Han and other ethnic groups, they even accepted some Chinese and other language education. Basically, the language and script of the nation are still used. After the rapid development of China's society and economy, the Han nationality occupied the dominant position of the society, and the Han culture education was greatly promoted and popularized. When the ethnic minorities first learned and contacted the Han culture, it did promote it to a certain extent. The development of language has formed a minority Chinese dialect with local characteristics. However, with various social contradictions in development and people's lack of attention, minority language cultures lacking guidance have begun to decline, gradually losing their development direction and becoming Endangered language. Generally speaking, Yunnan minority language culture is an intangible cultural heritage indispensable in China and even the whole world. The diversity of language and culture is suffering from the development of modern society. How to correctly guide the development of Yunnan minority languages and the inheritance of culture, It has gradually become an important national and social issue concerning China's social and cultural development and cultural heritage.

\section{Analysis on the Endangered Causes of Minority Language and Culture in Yunnan}

Endangered language, according to Wikipedia's explanation: human beings as an important social language in the development process, due to social development, ethnic migration and other reasons, the number of people using it has gradually decreased, and is about to become extinct. The main forming factors are: (1) Loss of state form. (2) The number of users decreased caused by various factors such as differentiation and integration of the two ethnic groups, social transformation, or the use of mixed and scattered. (3) In a collision between the two languages, it is weak, or not forming their own unique writing system, can not meet the daily communication and social complex communication requirements. (4) Years of use of the language, whether they have their own loyal users. (5) Under the influence of external conditions, it is gradually weakened by the influence of globalization factors. Combining these reasons, under the combined influence of various factors, if a group is able to resist the impact, it is possible to abandon the language currently used and let its next generation learn the mainstream language. All in all, the causes of endangered languages are not the same due to various uncertainties.

Comprehensive analysis of the current endangered situation of Yunnan minority languages and cultures, its causes are: (1) Foreign cultural shocks, leading young people tend to seek external development, more inclined to Chinese learning. With the continuous development of the modern network society, minority languages have been severely impacted, and more and more young people have begun to walk out of the country. After many young people go out, fewer and fewer people use local language to communicate, which ultimately leads to endangered language. (2) The number of users is reduced. This refers not only to the users of the national language, but also to the reduction of the number of people in a few areas. (3) The configuration of bilingual teachers in the education process can not meet the actual needs. (4) The population is aging, young people tend to use Chinese, and older people who use their own language are gradually decreasing. (5)(5) Language protection is too utilitarian, and sufficient economic support is needed in the process of ethnic 
minority protection of endangered languages, so business operations cannot be avoided, and too fierce commercial competition casts a heavy commercial atmosphere on the protection of endangered languages. Business atmosphere. (6) Failure to fully use modern technology. Nowadays, the information society has been developed at a high speed. It is completely unable to meet the demand simply by relying on backward propaganda and protection methods.

\section{Protection of Endangered Languages of Ethnic Minorities in Yunnan and the Inheritance of National Culture}

In view of the current situation of ethnic minority culture and cultural heritage in Yunnan Province and the development of related protection work, the author believes that it is necessary to establish a comprehensive language protection mechanism in a targeted manner, which can be divided into the following aspects:

\subsection{Research on Endangered Languages}

First of all, established a special protection institution for the endangered languages of ethnic minorities in Yunnan, and then actively went deep into the settlements of ethnic minorities in Yunnan, conducted research activities on local endangered languages, and conducted in-depth exploration of the history of local cultural development, thus, we have a certain understanding of the importance of the endangered language in the history of the development of the national culture, and finally further classify the endangered languages of ethnic minorities. At present, China has begun to pay attention to the problem of endangered languages of ethnic minorities in Yunnan, and has adopted a series of protective measures, which have indeed brought about a certain turning point in the endangered languages of Yunnan ethnic minorities. However, at the same time of cultural inheritance, there is still a crisis of extinction. As a carrier of ethnic minority culture inheritance, especially the culture unique to some ethnic minorities, such as the unique folk song culture of some ethnic minorities, only through the unique language of ethnic minorities can the content of the folk songs be displayed in order to show their original charm. If the language of the minority disappears, then these affiliated cultures will disappear. Another example is the unique witch language of ethnic minorities, which originally represented the important religious culture of the ethnic group. If the native language disappears, the same witchcraft has no original ecological significance. In general, the inheritance of minority culture is closely related to the form of cultural existence. Since the current minority culture relies mainly on the word of mouth, this method is easily affected by many factors, and language is a key influencing factor. Therefore, in view of the endangered language and national culture of ethnic minorities in Yunnan, we can focus on the research and collection of many different minority language-related materials, and produce relevant image files so that they can be well preserved.

\subsection{Establishing A Database of Endangered Languages of Ethnic Minorities in Yunnan}

Due to the particularity of ethnic minority endangered languages and their relatively complex language environment, it is necessary to establish a database of minority languages in a targeted manner, this will help ethnic minorities to learn from, inherit and develop in terms of policies, economic methods, and cultural protection. Therefore, relevant staffs members are required to carry out dynamic tracking and monitoring of minority languages, and collect, organize, and classify and archive them. Finally, digital media and web-based information technology can be used to dynamically store important data. What needs to be added here is that in the process of building a database of endangered languages of ethnic minorities, only the joint efforts of multi-disciplinary 
technical staff and researchers can truly achieve the purpose of effectively strengthening the use of ethnic minority endangered languages, and then truly establish a dynamic information database that effectively promotes the development and inheritance of minority cultures.

\subsection{Establish An Endangered Language Ecological Protection Zone}

As one of the important representatives of national culture, minority languages are the milestones in the development of the history and culture of the nation and have precious historical value. Therefore, it is possible to dig deep into the endangered languages of ethnic minorities, comprehensively explore the minority cultures, and fully grasp the development track of minority cultures and the cultural development situation of the era. In addition, while minority languages reflect the history of national development, they also reflect the cultural connotations, manifestations and rheological trends accumulated by ethnic minorities in their development, and their close relationship with the evolution of other national languages. Therefore, a good language use environment is the key to protecting the endangered language of ethnic minorities. Therefore, it is necessary to establish a special language protection zone. Through this special language protection zone, the promotion of endangered languages in the region will eventually lead to the protection of minority languages in Yunnan.

\subsection{Promote and Implement "Bilingual" Education and Decentralize Cultural Rights}

Judging from the existing experience of the protection of endangered languages of foreign minorities, the rational promotion and implementation of "bilingual" will help to protect and develop the minority language. In combination with the current "bilingual" education status of ethnic minorities in China, although it has been emphasizing the development of "bilingual" education, emphasizing the establishment of minority language rights, in terms of the status quo, there are still problems such as slow communication between the lower and upper levels, low efficiency of policy implementation, and insufficient teacher resources. Therefore, to comprehensively accelerate the pace of protecting ethnic minority endangered languages, there is still much work to be done to maintain and increase the vitality of the sustainable development of ethnic minorities. Therefore, it is necessary to provide a series of necessary conditions for the development of ethnic minority endangered languages. This requires the attention of the state and the decentralization of the rights of ethnic minorities in administration, justice and education. In addition, local support and cooperation are needed, and relevant language education and training are actively carried out to encourage the use of the national language in the younger generation, thus injecting fresh vitality into the development of minority languages and cultures. In addition, government agencies need to decentralize cultural rights. Minority culture is not only attributed to the nation, but also belongs to the whole society and all mankind. Therefore, it is necessary to decentralize relevant cultural rights, so as to mobilize the enthusiasm of the people and promote the all-round healthy development of minority culture. In this process, it is especially necessary to use local governments and civil society to establish a series of cultural museums, hand workshops and language classes. In addition, it is necessary to realize that ethnic minorities need to have their own cultural rights and need their own cultural museums to fully display their rich and excellent culture, which can arouse national pride and self-confidence and stimulate the national pride of young people, better to join in the construction and development of the nation. 


\subsection{Establish and Improve the Law on the Protection of Ethnic Minorities' Endangered Languages and Cultures}

The law is the basis for protecting the basic rights of citizens and maintaining social stability. Therefore, in order to better protect the endangered languages of ethnic minorities and further promote the inheritance and development of minority cultures, it is necessary to further establish and improve the legal system for ethnic minority endangered languages. In this respect, it has been verified from the smooth revival of the endangered language Maori language in New Zealand. In combination with the current situation in China, the laws on language and writing are still not perfect. In the "General Languages and Characters Law of the People's Republic of China", although There are provisions on the use of minority languages and scripts, but they do not involve the protection of ethnic minority endangered languages, nor do they have any separate bills in this regard. Nowadays, with the growing dangers of ethnic minority endangered culture, the call for the introduction of relevant laws is getting higher and higher. Although the Civil Affairs Commission has also promulgated the corresponding "Opinions on Doing a Good Job in Minority Languages and Writings", this policy In the meantime, it only guides the regulation of minority languages, but there is no opinion on the protection of minority languages in special areas. Therefore, considering the development trend of the country's future culture and starting from the inheritance and development of minority culture, the relevant institutions need to formulate a A comprehensive set of protection laws for endangered languages of ethnic minorities, combined with realistic dynamics, has been continuously improved, thus truly establishing a system of endangered language protection for ethnic minorities with socialism with Chinese characteristics.

\section{Conclusion}

Throughout the whole text, in general, the protection of the endangered languages of ethnic minorities in Yunnan and the inheritance of national culture are not only related to the history and culture of Yunnan ethnic minorities and the key to the survival and cultural development of the nation, but also needs to be analyzed from a national perspective and a social perspective, and actually makes actions from various aspects, and needs to enlarge this problem to a realistic philosophical issue concerning people's livelihood and social harmony. On the whole, exploring the protection of endangered languages and the inheritance of national culture of Yunnan ethnic minorities in the current reality, studying specific feasibility methods is not only the necessary way to maintain the diversity of our country's national culture, but also the arduous and glorious great task of inheriting the intangible cultural heritage of the Chinese nation, which has been handed over to us by our long history.

\section{References}

[1] Jianfei Xiao, Haichun Liu, Protection of Minority Languages in the Protection of Waste Material Cultural Heritage[J]. Hanshan Teachers College, 2014, (5): 76-80

[2] Li Li, Research on the Status Quo and Countermeasures of Minority Language Protection[J]. Journal of Jiangsu Second Normal University (Social Sciences), 2014, (7): 42-45

[3] Qiang Li, Protection of Endangered Languages of Ethnic Minorities in Yunnan and Ethnic Cultures in Yunnan[J]. Journal of Yuxi Teachers College,2015,(3):22-24

[4] Yan Wang, Yujiang Zhang. The Inheritance and Protection of Minority Dialects in the New Era-Taking Zhenchao Kucong and Buyuan Jinuo as Examples[J]. Guizhou Ethnic Studies, 2018, 39(03): 212-215.

[5] Yirong Wang, Yan Chen. Analysis on the Ways of Protection and Inheritance of Minority Languages and Characters [J]. Journal of Frontiers, 2014(Z7): 206-207.

[6] Hongliang Shi, Yunbao Li. Protection and Inheritance of Yunnan Minority Dramas[J]. Academic Research, 2015(08): 140-145. 
[7] Xianle Li, Fang Liu. Significance and Ways of Developing the Economic Value of Minority Languages_-Taking Tourism in Ethnic Areas as an Example[J]. Jianghan Academic Journal, 2013, 32(05): 56-61. 